\title{
Diagnostic reproducibility of temporomandibular joint using magnetic resonance imaging at 0.5 and 1.5 Tesla
}

\section{Reprodutibilidade de diagnósticos da articulação temporomandibular utilizando imagem por ressonância magnética de 0,5 e 1,5 Tesla}

\author{
Mathias P Fontana* \\ Nádia A. Arús* \\ Mariana B. Vizzotto* \\ Priscila F. da Silveira* \\ Heloísa E. D. Silveira* \\ Heraldo L. D. Silveira*
}

\section{Abstract}

Introduction: magnetic resonance imaging is described as the reference standard for the evaluation of temporomandibular joint soft tissues; however, the literature shows conflicting results regarding the reproducibility of this method. Objective: this study aimed to assess the reproducibility of temporomandibular joint diagnoses using magnetic resonance imaging at 0.5 and 1.5 Tesla. Methods: a trained observer analyzed 212 temporomandibular joint images (134 at $0.5 T$ and 78 at 1.5T) and diagnosed the presence or absence of nine conditions. Results: overall agreement was over $80 \%$ in both magnetic resonance units, with no significant differences $(P>0.05)$. Images at $0.5 T$ and $1.5 T$ provided excellent reproducibility for anterior disc displacement without reduction ( $\kappa=0.82$ and 0.80 , respectively), hypermobility $(\kappa=0.84$ and 0.90$)$, and hypomobility $(\kappa=0.80$ and 0.95), while fair to moderate values were obtained for anterior disc displacement with reduction $(\kappa=0.48$ and 0.42 ) and disc shape changes ( $\kappa=0.45$ and 0.37 ). Conclusion: magnetic resonance imaging diagnoses at $0.5 \mathrm{~T}$ and $1.5 T$ presented good agreement. However, the lowest reproducibility for anterior disc displacement with reduction and disc shape change reveals the difficulty to diagnose these disorders.

Keywords: Magnetic Resonance Imaging. Temporomandibular Joint. Temporomandibular Joint Disorders. Reproducibility of results.

\section{Introduction}

The clinical diagnosis of temporomandibular disorders (TMD) is highly complex and often requires complementary imaging examinations to provide conclusive findings. Magnetic resonance imaging (MRI) has been described as the method of choice to assess temporomandibular joint (TMJ) soft tissues ${ }^{1-4}$. MRI is also useful to examine cortical bone, producing results that can be compared in quality to computed tomography (CT) and cone beam computed tomography (CBCT), allowing the examination of both hard and soft TMJ tissues in one single image method ${ }^{5-7}$.

The TMJ conditions usually evaluated in MRI are position and shape of the joint disc. Disc displacement is related to other degenerative disorders (e.g.; disc shape change, condyle change, joint effusion, and condylar mobility), and the most severe changes are strongly linked to anterior disc displacement without reduction $(\mathrm{DDWR})^{8-15}$. Even though MRI is considered appropriate to examine the TMJ, research has reported discrepancies between MRI-based and clinical diagnoses ${ }^{1,16-22}$. Additionally, studies that evaluated the reproducibility of this method indicate the occurrence of conflicting values $^{23-29}$. This may be due to two main factors: image quality and observer skills. The first includes technical specifications of the equipment used such

\footnotetext{
* Departamento de Cirurgia e Ortopedia, Divisão de Radiologia e Imaginologia Oral, Faculdade de Odontologia, Universidade Federal do Rio Grande do Sul, Porto Alegre, RS, Brasil.
} 
as magnetic field strength, surface coil type, and acquisition sequence adopted ${ }^{5,730-32}$. For Stehling et al. ${ }^{32}$ (2007) and Schmid-Schwap et al. ${ }^{31}$ (2009), high field MRI generates better quality images when the aim is to examine cortical bone and assess joint disc shape. The authors also maintain that these images afford better diagnosis accuracy, which is an essential factor in clinical decision-making. In turn, Sarrat et al. ${ }^{7}$ (1999) and Karlo et al. ${ }^{5}$ (2012) have concluded that MRI is useful to visualize TMJ hard tissues, as long as an appropriate acquisition sequence is used, while Ahmad et al. ${ }^{33}$ (2009) and Alkhader et al. ${ }^{29}$ (2010) consider the method limited when compared to CT and CBCT.

The second main factor in diagnosis reliability is related to observer performance. In this sense, some authors have reported that training sessions and the definition of clear diagnosis criteria increase MRI reproducibility ${ }^{24,26,34,35}$. Furthermore, lower reproducibility values were detected in studies that assessed the performance of observers from different clinical centers who had not been trained ${ }^{23,25}$. For Nebbe et al. ${ }^{25}$ (2000), agreement ranged from slight to substantial for the diagnosis of anterior disc displacement with reduction (DDR) and normal disc position ( $\kappa$ ranging between 0.15 and $0.67)$, while the agreement for DDWR was excellent $(\kappa=0.91)$. Butzke et al. ${ }^{23}$ (2010) found low intraand inter-observer reproducibility for most diagnoses ( $\kappa$ between 0.00 and 0.37 ), and the best agreement was observed for DDWR $(\kappa=0.58)$.

Considering the discrepancies between agreement values reported in the literature and the lack of research using MRI obtained at different magnetic field strengths, the present study assesses the diagnostic reproducibility of temporomandibular joint using MRI at 0.5 and 1.5 Tesla.

\section{Materials and methods}

\section{Patient exams}

The Research Ethics Committee of the Federal University of Rio Grande do Sul (UFRGS), Brazil, approved this study (protocol number 120.620). The sample included all $236 \mathrm{MRI}$ examinations of the TMJ from the database of a radiology center in Brazil performed in a 5 -year period. From these examinations, 152 were acquired using a $0.5 \mathrm{~T}$ device (Gyroscan ${ }^{\mathrm{TM}}$ T5-NT, Philips, Amsterdam, The Netherlands) and 84 were obtained using a $1.5 \mathrm{~T}$ device (Magnetom ${ }^{\mathrm{TM}}$ Avanto, Siemens, Erlangen, Germany). Both devices used TMJ surface coils to acquire images. Acquisition sequences comprised $\mathrm{T} 1$ and $\mathrm{T} 2$ for $0.5 \mathrm{~T}$ images, and $\mathrm{T} 1, \mathrm{~T} 2$, and $\mathrm{PD}$ for $1.5 \mathrm{~T}$ images. The inclusion criterion was the absence of motion artifacts. From the total number of exams selected initially, $24(10.2 \%)$ were excluded (18 at $0.5 \mathrm{~T}$ and six at $1.5 \mathrm{~T})$.

\section{Video preparations}

All images used were saved as DICOM files and processed in the eFilm Lite ${ }^{\mathrm{TM}}$ 1.5.2 software (Merge Healthcare, eFilm, Milwaukee, USA), which creates videos for examination purposes. One video was processed for each TMJ, resulting in 212 videos (134 at $0.5 \mathrm{~T}$ and 78 at $1.5 \mathrm{~T}$ ). The $0.5 \mathrm{~T}$ videos presented the following visualization sequence: coronal slices at T1 and T2 (closed-mouth) and sagittal slices at T1 and T2 (closed and open-mouth). For images obtained at $1.5 \mathrm{~T}$, the video sequences were coronal slices at $\mathrm{T} 1$ and $\mathrm{T} 2$ (closed-mouth) and sagittal slices at PD and T2 (closed and open-mouth).

\section{Image evaluations}

The videos were evaluated in a workstation by a previously trained dentist specialized in Oral Radiology. Training consisted on the use of a digital learning object that presented morphology concepts and TMJ changes, apart from exercises to assess knowledge. The images were evaluated at the following two times: at first, $0.5 \mathrm{~T}$ and $1.5 \mathrm{~T}$ videos were analyzed in a 10-day period. After a 15-day interval, this process was repeated. Each TMJ was evaluated for the presence or absence of nine conditions, according to the following criteria: 1. Normal disc position - posterior band of the disc located in the 11- to 12-o'clock range relative to the condyle in the closed-mouth sagittal view, and the articular disc reaching the condyle top in the open-mouth view (Figure 1A); 2. Anterior disc displacement with reduction (DDR) - posterior band of the articular disc located in front of the 11- and 12-o'clock range relative to the condyle in closed-mouth sagittal view (Figure 1B), and disc recapture observed in open-mouth view when the articular disc reaches the condyle top (Figure 1C); 3. Anterior disc displacement without reduction (DDWR) - posterior band of the articular disc located in front of the 11 - to 12 -o'clock range relative to the condyle in closed-mouth sagittal view, no recapture in open-mouth view (Figure 1D); 4. Medial or lateral disc displacement (M/LD) - articular disc not centered on the condyle, but medially or laterally displaced in closed-mouth coronal view (Figure $1 \mathrm{E}) ;$ 5. Disc shape change - absent in biconcave discs whose anterior and posterior bands were clearly defined and separated by a thin intermediate zone. Biconvex, flat, and folded shapes characterize disc change (Figure $1 \mathrm{~F}) ;$ 6. Condyle change - manifested as flattening, osteophyte, erosion, subcortical sclerosis, and subcortical cyst (Figure 1G); 7 . Hypermobility - condyle center located anterior to the articular eminence center in open-mouth sagittal view (Figure 1H); 8. Hypomobility - condyle center located posterior to the articular eminence in open-mouth sagittal view (Figure 1D); and 9. Joint effusion - hypersignal due to the presence of synovial fluid in articular compartments observed in T2 images (Figure 1F). 


\section{Statistical analyses}

The reproducibility of exams carried out at both times was evaluated using Cohen's $\kappa$ coefficient. The chi-square test with continuity correction was used to analyze percent agreement difference between $0.5 \mathrm{~T}$ and $1.5 \mathrm{~T}$ images. Statistical analyses were conducted using the SPSS v.19 software (SPSS Inc., Chicago, USA).

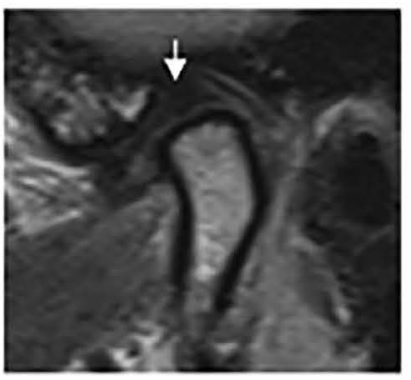

A

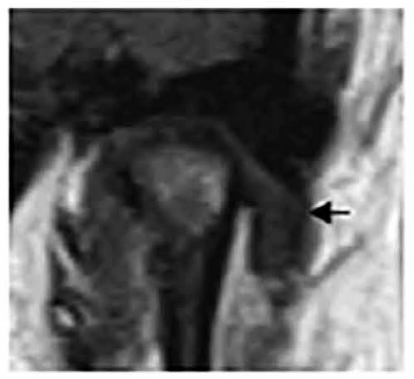

E

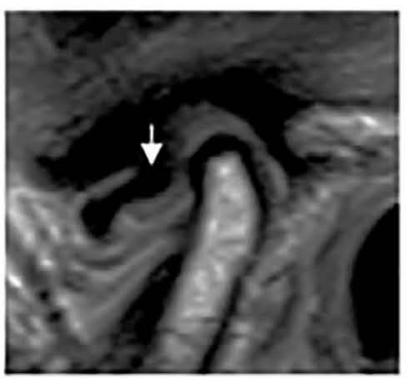

B

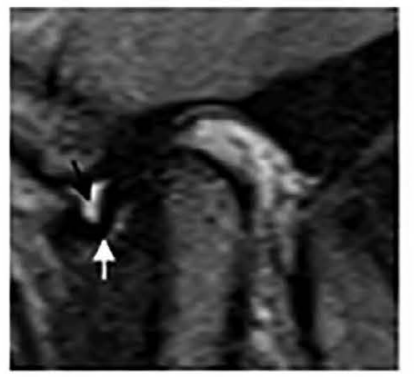

F

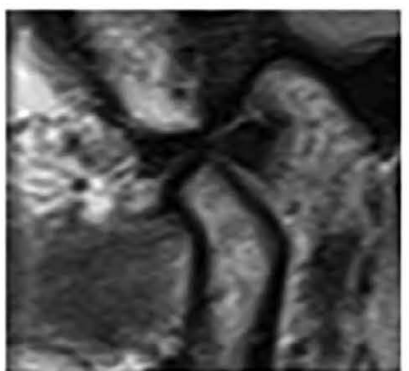

$\mathrm{C}$

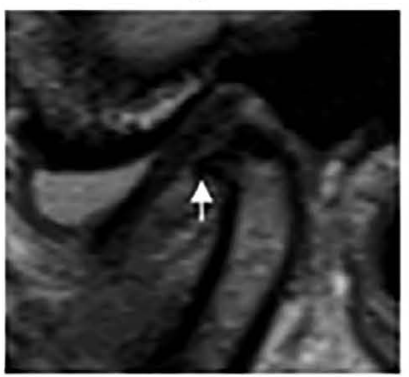

G

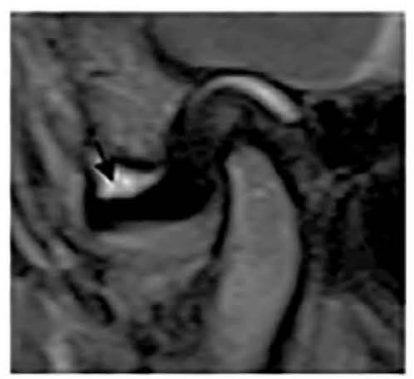

D

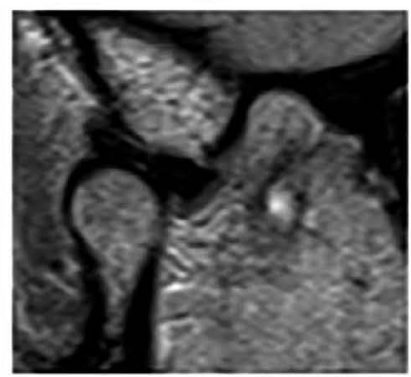

$\mathrm{H}$

Figure 1 - Conditions evaluated in the study: A, Sagittal slice (T1) showing normal position and shape of the articular disc in closed-mouth view the posterior band of the articular disc is near the 12 o'clock position, relative to the condyle (white arrow); B, Sagittal slice (T1) showing anterior disc displacement in closed-mouth view - the posterior band of the articular disc is far beyond the 11-to 12-o'clock range, relative to the condyle (white arrow); C, Sagittal slice (T1) showing disc recapture in open mouth view, characterizing DDR; D, Sagittal slice (T1), open-mouth view of a disc that remains anteriorly displaced, characterizing DDWR - notice the presence of condyle hypomobility and joint effusion (black arrow); E, Coronal slice (T1), closed-mouth view showing lateral disc displacement (black arrow); $\mathbf{F}$, Sagittal slice (T2), closed-mouth view showing the anteriorly displaced and folded disc (white arrow) and joint effusion (black arrow); G, Sagittal slice (T1), closed-mouth view showing the condyle of changed shape and the presence of osteophyte (white arrow); $\mathbf{H}$, Sagittal slice (T1), open-mouth view showing that the condyle exceeds the limits of the articular eminence, characterizing hypermobility

Fonte: elaboração dos autores

\section{Results}

Table 1 shows the percent agreement between initial and second observations of images. The agreement in all conditions used as criteria between both observations was recorded for $90(42.5 \%)$ out of the 212 TMJs, wherein $54(40.3 \%)$ were $0.5 \mathrm{~T}$ and $36(46.2 \%)$ were $1.5 \mathrm{~T}$ images, with no statistically significant differences $(\mathrm{P}>0.05)$. When disorders were considered individually, analyses showed high agreement for all criteria in images obtained at both field strengths. The highest value was observed for hypomobility in images acquired at $1.5 \mathrm{~T}(97.4 \%)$, while the lowest was seen for DDR in $0.5 \mathrm{~T}$ images $(80.6 \%)$. The chi-square test with continuity correction indicated no statistically significant difference between field strengths $(\mathrm{P}>0.05)$.

Table 1 - Percent agreement in the diagnosis of TMJ conditions by MRI acquired at $0.5 T(N 134)$ and $1.5 T(N 78)-\chi_{0.05: 1}^{2}=3.84$

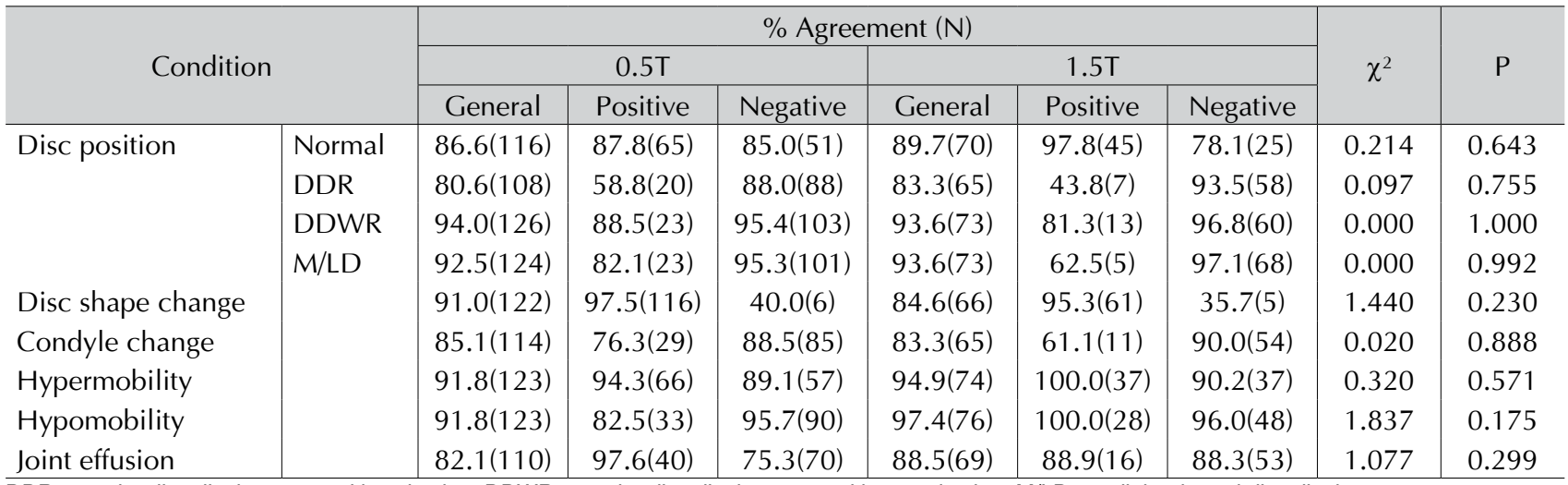

DDR: anterior disc displacement with reduction; DDWR: anterior disc displacement without reduction; M/LD: medial or lateral disc displacement.

Fonte: elaboração dos autores. 
The kappa coefficient was calculated for each condition (Table 2). Moderate reproducibility was observed for DDR in $0.5 \mathrm{~T}$ and $1.5 \mathrm{~T}$ images $(\kappa=0.48$ and 0.42 , respectively), while excellent results were obtained for DDWR ( $\kappa=0.82$ and 0.80 ), hypermobility $(\kappa=0.84$ and 0.90$)$, and hypomobility $(\kappa=0.80$ and 0.85 ). Substantial reproducibility was observed for detection of normal disc position $(\kappa=0.73$ and 0.78 ), $\mathrm{M} / \mathrm{LD}$ ( $\kappa=0.78$ and 0.64 ), and joint effusion $(\kappa=0.63$ and 0.70$)$. In turn, reproducibility of condyle change was substantial using images obtained at $0.5 \mathrm{~T}(\kappa=0.64)$ and moderate at $1.5 \mathrm{~T}(\kappa=0.52)$. Reproducibility of the detection of disc shape change was moderate $(\kappa=0.45)$ using $0.5 \mathrm{~T}$ images and fair $(\kappa=0.37)$ using $1.5 \mathrm{~T}$.

Table 2 - Reproducibility in the diagnosis of TMJ conditions by MRI acquired at 0.5T (N 134) and 1.5T (N 78)

\begin{tabular}{l|l|c|c|c|c|}
\hline \multicolumn{2}{|c|}{ Condition } & \multicolumn{2}{c|}{$0.5 T$} & \multicolumn{2}{c}{$1.5 T$} \\
\cline { 3 - 6 } \multicolumn{2}{|c|}{} & kappa & (SE) & kappa & (SE) \\
\hline Disc position & Normal & 0.73 & 0.060 & 0.78 & 0.072 \\
& DDR & 0.48 & 0.088 & 0.42 & 0.131 \\
& DDWR & 0.82 & 0.063 & 0.80 & 0.086 \\
Disc shape change & & 0.78 & 0.068 & 0.64 & 0.152 \\
Condyle change & & 0.45 & 0.131 & 0.37 & 0.142 \\
Hypermobility & & 0.64 & 0.074 & 0.52 & 0.116 \\
Hypomobility & & 0.84 & 0.048 & 0.90 & 0.050 \\
Joint effusion & & 0.80 & 0.058 & 0.95 & 0.038 \\
\hline
\end{tabular}

DDR: anterior disc displacement with reduction; DDWR: anterior disc displacement without reduction; M/LD: medial or lateral disc displacement; SE: standard error.

Fonte: elaboração dos autores.

Table 3 shows the position of the joint disc in sagittal view observed in the first and second analyses using images obtained at $0.5 \mathrm{~T}$ and $1.5 \mathrm{~T}$.

Table 3 - Classification of disc position in sagittal slices at the first and second evaluations using MRI acquired at $0.5 T(\mathrm{~N}$ 134) and 1.5T ( $\mathrm{N} 78$ )

\begin{tabular}{l|c|c|c|c|c|c|c|}
\hline \multicolumn{7}{c}{ Second evaluation } \\
\hline \multicolumn{2}{c|}{ Normal } & \multicolumn{2}{|c|}{ DDR } & \multicolumn{2}{c}{ DDWR } & \multicolumn{2}{c}{ Total } \\
\hline 0.5T & $1.5 \mathrm{~T}$ & $0.5 \mathrm{~T}$ & $1.5 \mathrm{~T}$ & $0.5 \mathrm{~T}$ & $1.5 \mathrm{~T}$ & $0.5 \mathrm{~T}$ & $1.5 \mathrm{~T}$ \\
\hline
\end{tabular}

\begin{tabular}{|c|c|c|c|c|c|c|c|c|c|}
\hline \multirow{4}{*}{ 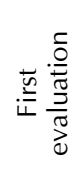 } & Normal & 65 & 45 & 9 & 1 & 0 & 0 & 74 & 46 \\
\hline & DDR & 9 & 7 & 20 & 7 & 5 & 2 & 34 & 16 \\
\hline & DDWR & 0 & 0 & 3 & 3 & 23 & 13 & 26 & 16 \\
\hline & Total & 74 & 52 & 32 & 11 & 28 & 15 & 134 & 78 \\
\hline
\end{tabular}

DDR: anterior disc displacement with reduction; DDWR: anterior disc displacement without reduction.

Fonte: elaboração dos autores.

\section{Discussion}

MRI is the method of choice to examine the TMJ, although the literature warns about a wide variation in diagnosis reproducibility. This varia- tion may be influenced by issues associated with the classification of the disorders evaluated and by characteristics of the observer ${ }^{23-29,34,35}$. However, it is known that other factors may also affect MRI quality and consequently interfere with reproducibility, such as magnetic field strength ${ }^{31,32}$. In this sense, this study assessed the reproducibility of the diagnosis of TMD using MRI at $0.5 \mathrm{~T}$ and $1.5 \mathrm{~T}$.

As a rule, high agreement was observed for each of the nine criteria, with percent values between $80.6 \%$ and $97.4 \%$, similar to those previously described by Tasaki et al. ${ }^{27}$ (1993) and Ahmad et al. ${ }^{33}$ (2009) (between $82 \%$ and 99\%). These high agreement values seem to suggest, at first, that MRI is a reliable method. Nevertheless, these values may not reflect the truth, due to either high or low prevalence numbers recorded for some conditions. For example, the high overall agreement observed for DDR using $0.5 \mathrm{~T}$ and $1.5 \mathrm{~T}$ images (80.6 and 83.3, respectively) is more likely due to the absence of positive findings than to confirmed occurrences, as shown by high negative agreement (88.0 and 93.5) and low positive agreement (58.8 and 43.8) (Table 1 ). The same may be said of the disc shape change criterion; however, opposite to DDR, the high overall agreement for this disorder is explained by the high positive agreement values (97.5 and 95.3), in spite of the low negative agreement values (40.0 and 35.7) (Table 1). This is why the $\kappa$ coefficient was used, since it considers the asymmetry of positive and negative agreement in all criteria used. In this sense, the $\kappa$ values were remarkably lower than percent agreement values (Table 2).

In the present study, high reproducibility was observed for DDWR ( $\kappa=0.82$ for $0.5 \mathrm{~T}$ and 0.80 for $1.5 \mathrm{~T}$ images) compared with DDR $(\kappa=0.48$ and 0.42 , respectively). This observation is in accordance with previously published results ${ }^{23,25,33}$. No anomaly initially diagnosed as DDWR was diagnosed as normal in the second examination, although the disorders first diagnosed as DDR were diagnosed at times as DDWR and at times as normal condition in the second evaluation (Table 3). This is associated with the higher detection of anterior disc displacement in open-mouth views since the disorder is inherently more easily detectable, which explains the high reproducibility of its diagnosis. Oppositely, the diagnosis of DDR requires the observation of the anteriorly displaced disc in the closed-mouth view and its return to normal position in open-mouth view. The difficulty to identify displaced disc in open-mouth views may lead the observer to mistake this change for normal disc, while the absence of a positive identification of disc recapture may erroneously lead to the conclusion that the condition seen is DDWR. Therefore, the mere examination of images does not suffice to reach conclusive diagnosis; in fact, in addition to imaging techniques, diagnostic accuracy requires the positive detection of clinical signs of $\mathrm{DDR}^{18,20}$. 
Tasaki et al. ${ }^{27}$ (1993) and Orsini et al. ${ }^{26}$ (1997) observed good intra-observer agreement to detect joint disc shape change $(\kappa=0.65$ and 0.79 , respectively), but Butzke et al. ${ }^{23}$ (2010) did not report any agreement for this disorder $(\kappa=0.03)$. The reproducibility values obtained for this disorder in the present study were the lowest, with moderate agreement for $0.5 \mathrm{~T}$ images $(\kappa=0.45)$ and fair agreement for $1.5 \mathrm{~T}$ images $(\kappa=0.37)$. This low reproducibility may be explained by the small number of cases with no alteration and the lower repetition of these diagnoses (Table 1). Another aspect that may have contributed to the low accuracy in detecting this disorder was the difficulty to visualize the anatomic outlines of the articular disc in both field strengths.

Substantial agreement was obtained in the detection of condyle change using $0.5 \mathrm{~T}$ images $(\kappa=0.64)$, while $1.5 \mathrm{~T}$ images provided average agreement $(\kappa=0.52)$. These values were higher than those obtained by Ahmad et al. ${ }^{33}(2009)(\kappa=0.47)$ and Butzke et al. ${ }^{23}(2010)(\kappa=0.05)$, and lower than the agreement reported by Tasaki et al. ${ }^{27}$ (1993) $(\kappa=0.86-0.95)$ and Salé et al. ${ }^{28}(2014)(\kappa=0.97)$. These differences put to the test the actual usefulness of MRI to inspect TMJ hard tissue. While some authors consider the technique appropriate as long as a suitable T1 weighted acquisition sequence is used ${ }^{5,7}$, others believe that the method is limited compared with CT, CBCT, and arthrosco$\mathrm{py}^{33,36}$. However, MRI does not use ionizing radiation and therefore should be preferable to CT, as established by the ALARA (as low as reasonably achievable) principle. According to this principle, any exposure to radiation must be justified in relation to other diagnostic alternatives and the benefit to the patient should be greater than the potential harm that may be caused. Therefore, further studies should be carried out to test different protocols that may improve the interpretation of cortical bone, confirming MRI as the best alternative to CT and $\mathrm{CBCT}$ in cases requiring the examination of bone surfaces.

Evidence of the association between joint effusion and anterior disc displacement have been described in the literature ${ }^{9-11}$. Hypersignal in articular compartments, which indicates joint effusion, is relatively easy to detect in T2 weighted images. The reproducibility of this disorder was hereby substantial ( $\kappa=0.63$ for $0.5 \mathrm{~T}$ images, and 0.70 for $1.5 \mathrm{~T}$ images), similar to the value obtained by Ahmad et al. ${ }^{33}$ (2009) $(\kappa=0.64)$, but lower than that reported by Salé et al. ${ }^{28}(2014)(\kappa=0.95)$ and Roh et al. ${ }^{10}(2012)$ $(\kappa=0.85)$.

The hypo- and hypermobility criteria presented excellent reproducibility indices in both field strengths, with $\kappa$ between 0.80 and 0.95 , respectively. These values are explained by the fact that the relationship between the condyle and the articular eminence is easily detectable (Figure $1 \mathrm{D}$ and $1 \mathrm{H}$ ) and the diagnosis criteria is well defined. However, these results are not very relevant considering the extent the condyle overlaps the articular eminence does not always bear a good correspondence with mouth opening, which is a clinically established criterion. For Kalaykova et al. ${ }^{37}$ (2006), the position of the condyle alone is not a good predictor of functional signs of hypermobility. The authors believe that condylar position associated with a particular line of action of the masticatory muscles produces functional signs of hypermobility.

The present study did not detect significant differences between percent agreement values obtained using $0.5 \mathrm{~T}$ and $1.5 \mathrm{~T}$ images $(\mathrm{P}>0.05)$. Stehling et al..$^{32}$ (2007) and Schmid-Schwap et al. ${ }^{31}$ (2009) also compared agreement using images obtained with different field strengths, although they used $1.5 \mathrm{~T}$ and 3.0 T images. In both studies, 3.0 T images produced better qualitative findings. However, in the first study the authors did not observe differences between $0.5 \mathrm{~T}$ and $1.5 \mathrm{~T}$ for disc position and mobility, while the second study showed no statistically significant difference for agreement in the detection of disc shape ( $\kappa=0.73$ for $1.5 \mathrm{~T}$ and 0.76 for 3.0T images).

Another important factor that influences reproducibility studies is observer performance. Previous training and the adoption of a simplified classification of disorders improved reproducibility compared with studies in which observers did not attend a review program or classification of disorders was excessively all-encompassing $24,26-28,33-35$. In the present study, the observer went through training sessions using a digital learning object and answered exercises to assess knowledge. Additionally, the nine conditions assessed were ranked dichotomically for the presence or absence of a change, which improved the agreement values obtained.

The limitations of this study include the fact that two separate samples were used, one for each MRI device, which makes it impossible to compare datasets. The percent agreement between units is the only comparable outcome, while the $\kappa$ index must be analyzed individually.

Strengths of this study are the large sample size. Most studies on the reproducibility of MRI to detect TMJ disorders used small samples, between 24 and $149^{23-27,31,33}$. In the present study, the sample comprised all images stored in the database of a private radiological center, taken in a 5 -year period. This comparatively larger sample offered more consistency, considering a total of 212 TMJs were examined (134 0.5T images and $781.5 \mathrm{~T}$ images). Moreover, although there are MRI units with higher field strengths, $0.5 \mathrm{~T}$ and $1.5 \mathrm{~T}$ are the devices most commonly found in Brazil and Latin America, and exams performed with these units are still a reality for these locations. In this sense, this study contributes to show how reproducible MRI can be and which disorders represent the greatest diagnostic challenge at these field strengths. 
Although the literature emphasizes the importance of diagnosing disc displacement and disc shape change for the clinical decision-making, considering these are the main reasons for requesting MRI, this study showed that precisely these disorders presented low reproducibility regardless of field strength. Based on the results of this study, it may be concluded that there was no significant difference in percent agreement values using $0.5 \mathrm{~T}$ and $1.5 \mathrm{~T}$ images. Both devices allowed reproducible diagnosis of TMJ disorders like DDWR, M/LD, condyle mobility, and joint effusion. However, the lower reproducibility found for DDR and disc shape change reveals that diagnosing these clinically relevant disorders is difficult for both $0.5 \mathrm{~T}$ and $1.5 \mathrm{~T}$ MRI.

\section{Resumo}

Introdução: a imagem por ressonância magnética é descrita como o exame de referência para a avaliação dos tecidos moles da articulação temporomandibular, entretanto, a literatura revela resultados conflitantes quanto à reprodutibilidade desse método. Objetivo: o objetivo do estudo foi avaliar a reprodutibilidade de diagnósticos da articulação temporomandibular utilizando a imagem por ressonância magnética de 0,5 e 1,5 Tesla. Métodos: um observador treinado analisou 212 imagens da articulação temporomandibular (134 em 0,5T e $78 \mathrm{em} \mathrm{1,5T)} \mathrm{e} \mathrm{diagnosticou} \mathrm{a} \mathrm{presença} \mathrm{ou}$ ausência de nove desordens. Resultados: a concordância geral foi superior a $80 \%$ em ambas as unidades de ressonância magnética, sem diferença significativa $(P>$ $0,05)$. As imagens em 0,5T e 1,5T obtiveram excelente reprodutibilidade para deslocamento anterior de disco sem redução ( $\kappa=0,82$ e 0,80 - respectivamente), hipermobilidade $(\kappa=0,84$ e 0,90$)$ e hipomobilidade $(\kappa$ $=0,80$ e 0,95), enquanto valores médios a moderados foram alcançados para deslocamento anterior de disco com redução ( $\kappa=0,48$ e 0,42$)$ e alteração de forma do disco ( $\kappa=0,45$ e 0,37). Conclusão: os diagnósticos de imagem por ressonância magnética de 0,5T e 1,5T apresentaram boa concordância, entretanto, a menor reprodutibilidade para deslocamento anterior de disco com redução e alteração de forma do disco revela a dificuldade do diagnóstico dessas desordens.

Palavras-chave: Imagem por ressonância magnética. Articulação temporomandibular. Transtornos da articulação temporomandibular. Reprodutibilidade dos testes.

\section{References}

1. Galhardo AP, da Costa Leite C, Gebrim EM, Gomes RL, Mukai MK, Yamaguchi CA, et al. The correlation of research diagnostic criteria for temporomandibular disorders and magnetic resonance imaging: a study of diagnostic accuracy. Oral Surg Oral Med Oral Pathol Oral Radiol 2013; 115(2):277-84.

2. Petersson A. What you can and cannot see in TMJ imaging - an overview related to the RDC/TMD diagnostic system. J Oral Rehabil 2010;37(10):771-8.
3. Poveda Roda R, Diaz Fernandez JM, Hernandez Bazan S, Jimenez Soriano Y, Margaix M, Sarrion G. A review of temporomandibular joint disease (TMJD). Part II: Clinical and radiological semiology. Morbidity processes. Med Oral Patol Oral Cir Bucal 2008;13(2):E102-9.

4. Kumar R, Pallagatti S, Sheikh S, Mittal A, Gupta D, Gupta S. Correlation between clinical findings of temporomandibular disorders and MRI characteristics of disc displacement. Open Dent J 2015;9:273-81.

5. Karlo CA, Patcas R, Kau T, Watzal H, Signorelli L, Muller L, et al. MRI of the temporo-mandibular joint: which sequence is best suited to assess the cortical bone of the mandibular condyle? A cadaveric study using micro-CT as the standard of reference. Eur Radiol 2012;22(7):7.

6. Ohkubo M, Sano T, Otonari-Yamamoto M, Hayakawa Y, Okano T, Sakurai K, et al. Magnetic resonance signal intensity from retrodiscal tissue related to joint effusion status and disc displacement in elderly patients with temporomandibular joint disorders. Bull Tokyo Dent Coll 2009;50(2):55-62.

7. Sarrat P, Cheynet F, Chossegros C, Orthlieb JD, Philip E, Carrasset S, et al. RMI of dysfunctional temporomandibular joint (TMJ). Value of gradient-echo T1 sequences in the evaluation of bony structures. J Radiol 1999;80(11):1543-54.

8. Amaral RO, Damasceno NN, de Souza LA, Devito KL. Magnetic resonance images of patients with temporomandibular disorders: prevalence and correlation between disc morphology and displacement. Eur J Radiol 2013;82(6):990-4.

9. Ogutcen-Toller M, Taskaya-Yilmaz N, Yilmaz F. The evaluation of temporomandibular joint disc position in TMJ disorders using MRI. Int J Oral Maxillofac Surg 2002;31(6):603-7.

10. Roh HS, Kim W, Kim YK, Lee JY. Relationships between disc displacement, joint effusion, and degenerative changes of the TMJ in TMD patients based on MRI findings. J Craniomaxillofac Surg 2012;40(3):283-6.

11. Orlando B, Chiappe G, Landi N, Bosco M. Risk of temporomandibular joint effusion related to magnetic resonance imaging signs of disc displacement. Med Oral Patol Oral Cir Bucal 2009;14(4):188-93.

12. Cortes D, Exss E, Marholz C, Millas R, Moncada G. Association between disc position and degenerative bone changes of the temporomandibular joints: an imaging study in subjects with TMD. Cranio 2011;29(2):117-26.

13. Dias IM, Coelho PR, Assis NM, Leite FP, Devito KL. Evaluation of the correlation between disc displacements and degenerative bone changes of the temporomandibular joint by means of magnetic resonance images. Int J Oral Maxillofac Surg 2012;41(9):1051-7.

14. Hirata FH, Guimaraes AS, Oliveira JX, Moreira CR, Ferreira ET, Cavalcanti MG. Evaluation of TMJ articular eminence morphology and disc patterns in patients with disc displacement in MRI. Braz Oral Res 2007;21(3):265-71.

15. Dias IM, Cordeiro PC, Devito KL, Tavares ML, Leite IC, Tesch ReS. Evaluation of temporomandibular joint disc displacement as a risk factor for osteoarthrosis. Int $\mathrm{J}$ Oral Maxillofac Surg 2016;45(3):313-7.

16. Brandlmaier I, Bertram S, Rudisch A, Bodner G, Emshoff R. Temporomandibular joint osteoarthrosis diagnosed with high resolution ultrasonography versus magnetic resonance imaging: how reliable is high resolution ultrasonography? J Oral Rehabil 2003;30(8):812-7.

17. Emshoff R, Brandlmaier I, Bosch R, Gerhard S, Rudisch A, Bertram S. Validation of the clinical diagnostic criteria for temporomandibular disorders for the diagnostic subgroup - disc derangement with reduction. J Oral Rehabil 2002; 29(12):1139-45. 
18. Manfredini D, Guarda-Nardini L. Agreement between Research Diagnostic Criteria for Temporomandibular Disorders and magnetic resonance diagnoses of temporomandibular disc displacement in a patient population. Int J Oral Maxillofac Surg 2008;37(7):612-6.

19. Yatani H, Sonoyama W, Kuboki T, Matsuka Y, Orsini MG, Yamashita A. The validity of clinical examination for diagnosing anterior disc displacement with reduction. Oral Surg Oral Med Oral Pathol Oral Radiol Endod 1998;85(6):647-53.

20. Yatani H, Suzuki K, Kuboki T, Matsuka Y, Maekawa K, Yamashita A. The validity of clinical examination for diagnosing anterior disc displacement without reduction. Oral Surg Oral Med Oral Pathol Oral Radiol Endod 1998;85(6):654-60.

21. Summa S, Ursini R, Manicone PF, Molinari F, Deli R. MRI assessment of temporomandibular disorders: an approach to diagnostic and therapeutic setting. Cranio 2014;32(2):131-8.

22. Pupo YM, Pantoja LL, Veiga FF, Stechman-Neto J, Zwir LF, Farago PV, et al. Diagnostic validity of clinical protocols to assess temporomandibular disc displacement disorders: a meta-analysis. Oral Surg Oral Med Oral Pathol Oral Radiol 122(5):572-86

23. Butzke KW, Chaves KDB, Silveira HED, Silveira HLD. Evaluation of the reproducibility in the interpretation of magnetic resonance images of the temporomandibular joint. Dentomaxillofac Radiol 2010;39(3):157-61.

24. Nagamatsu-Sakaguchi C, Maekawa K, Ono T, Yanagi Y, Minakuchi H, Miyawaki S, et al. Test-retest reliability of MRI-based disc position diagnosis of the temporomandibular joint. Clin Oral Investig 2012;16(1):101-8.

25. Nebbe B, Brooks SL, Hatcher D, Hollender LG, Prasad NG, Major PW. Magnetic resonance imaging of the temporomandibular joint: interobserver agreement in subjective classification of disc status. Oral Surg Oral Med Oral Pathol Oral Radiol Endod 2000;90(1):102-7.

26. Orsini MG, Terada S, Kuboki T, Matsuka Y, Yamashita A. The influence of observer calibration in temporomandibular joint magnetic resonance imaging diagnosis. Oral Surg Oral Med Oral Pathol Oral Radiol Endod 1997;84(1):82-7.

27. Tasaki MM, Westesson PL, Raubertas RF. Observer variation in interpretation of magnetic resonance images of the temporomandibular joint. Oral Surg Oral Med Oral Pathol 1993;76(2):231-4

28. Sale H, Bryndahl F, Isberg A. A 15-year follow-up of temporomandibular joint symptoms and magnetic resonance imaging findings in whiplash patients: a prospective, controlled study. Oral Surg Oral Med Oral Pathol Oral Radiol 2014;117(4):522-32

29. Alkhader M, Ohbayashi N, Tetsumura A, Nakamura S, Okochi K, Momin MA, et al. Diagnostic performance of magnetic resonance imaging for detecting osseous abnormalities of the temporomandibular joint and its correlation with cone beam computed tomography. Dentomaxillofac Radiol 2010;39(5):270-6

30. Manoliu A, Spinner G, Wyss M, Filli L, Erni S, Ettlin DA, et al. Comparison of a 32-channel head coil and a 2-channel surface coil for MR imaging of the temporomandibular joint at 3.0T. Dentomaxillofac Radiol 2016;45(4):20150420.

31. Schmid-Schwap M, Drahanowsky W, Bristela M, Kundi M, Piehslinger E, Robinson S. Diagnosis of temporomandibular dysfunction syndrome--image quality at 1.5 and 3.0 Tesla magnetic resonance imaging. Eur Radiol 2009;19(5):1239-45.

32. Stehling C, Vieth V, Bachmann R, Nassenstein I, Kugel H, Kooijman $\mathrm{H}$, et al. High-resolution magnetic resonance imaging of the temporomandibular joint: image quality at 1.5 and 3.0 Tesla in volunteers. Invest Radiol $2007 ; 42(6): 428-34$.
33. Ahmad M, Hollender L, Anderson Q, Kartha K, Ohrbach R, Truelove EL, et al. Research diagnostic criteria for temporomandibular disorders (RDC/TMD): development of image analysis criteria and examiner reliability for image analysis. Oral Surg Oral Med Oral Pathol Oral Radiol Endod 2009;107(6):844-60.

34. Orsini MG, Kuboki T, Terada S, Matsuka Y, Yamashita A, Clark GT. Diagnostic value of 4 criteria to interpret temporomandibular joint normal disc position on magnetic resonance images. Oral Surg Oral Med Oral Pathol Oral Radiol Endod 1998;86(4):489-97.

35. Provenzano M de M, Chilvarquer I, Fenyo-Pereira M. How should the articular disc position be analyzed? J Oral Maxillofac Surg 2012;70(7):1534-9.

36. Yura S, Harada S, Kobayashi K. Diagnostic accuracy on magnetic resonance imaging for the diagnosis of osteoarthritis of the temporomandibular joint. J Clin Diagn Res 2015;9(7):ZC95-7.

37. Kalaykova S, Naeije M, Huddleston Slater JJ, Lobbezoo F. Is condylar position a predictor for functional signs of TMJ hypermobility? J Oral Rehabil 2006;33(5):349-55.

\section{Endereço para correspondência:}

Mathias Pante Fontana

Rua Ramiro Barcelos, 2492, Laboratório de

Radiologia, 5ำ andar, Bairro Santana

90035-003 - Porto Alegre, RS, Brasil

Fone: (51) 33085199

E-mail: mathiaspante@hotmail.com

Recebido: 28/11/2016. Aceito: 23 /03/2017. 